\title{
Heat Shock-Induced Resistance against Pseudomonas syringae pv. tomato (Okabe) Young et al. via Heat Shock Transcription Factors in Tomato
}

\author{
Nur Akbar Arofatullah ${ }^{1}$, Morifumi Hasegawa ${ }^{2}$, , Sayuri Tanabata ${ }^{3}$, Isao Ogiwara ${ }^{1}$ \\ and Tatsuo Sato ${ }^{3, *}$ (D) \\ 1 United Graduate School of Agricultural Science, Tokyo University of Agriculture and Technology, \\ 3-5-8 Saiwai-cho, Fuchu-shi, Tokyo 183-8509, Japan; akbar1708@gmail.com (N.A.A.); \\ ogiwaraisao@gmail.com (I.O.) \\ 2 College of Agriculture, Ibaraki University, 3-21-1 Chuo, Ami, Inashiki, Ibaraki 300-0393, Japan; \\ morifumi.hasegawa.1@vc.ibaraki.ac.jp \\ 3 Center for International Field Agriculture Research and Education, College of Agriculture, \\ Ibaraki University, Ami 4668-1, Ami, Inashiki, Ibaraki 300-0331, Japan; sayuri.tanabata.i@vc.ibaraki.ac.jp \\ * Correspondence: sugar@mx.ibaraki.ac.jp; Tel./Fax: +81-29-888-8704
}

Received: 6 December 2018; Accepted: 18 December 2018; Published: 20 December 2018

\begin{abstract}
We investigated the role of heat shock transcription factors (Hsfs) during induction of defense response by heat-shock treatment (HST) in tomato. Leaf disease symptoms were significantly reduced at 12 and $24 \mathrm{~h}$ after HST, consistent with upregulation of pathogenesis-related (PR) genes PR1a2 and PR1b1 peaking at $24 \mathrm{~h}$ after treatment. These genes were upregulated at the treatment application site, but not in untreated leaves. In contrast to HST, inoculation of the first leaf induced systemic upregulation of acidic PR genes in uninoculated second leaves. Furthermore, heat shock element motifs were found in upstream regions of PR1a2, PR1b1, Chitinase 3, Chitinase 9, Glucanase $\mathrm{A}$, and Glucanase B genes. Upregulation of $H s f A 2$ and $H s f B 1$ peaked at $6 \mathrm{~h}$ after HST, $6 \mathrm{~h}$ earlier than salicylic acid accumulation. Foliar spray of heat shock protein 90 (Hsp90) inhibitor geldanamycin (GDA) induced PR gene expression comparable to that after HST. PR gene expression and defense response against Pseudomonas syringae pv. tomato (Pst) decreased when combining HST with Hsfs inhibitor KRIBB11. The Hsfs and PR gene expression induced by heat or GDA, together with the suppression of heat shock-induced resistance (HSIR) against Pst by KRIBB11, suggested a direct contribution of Hsfs to HSIR regulation in tomato.
\end{abstract}

Keywords: heat shock element; geldanamycin; KRIBB11; pathogenesis-related gene; salicylic acid; plant-pathogen interaction

\section{Introduction}

Plant disease resistance acquired under heat stress is known as heat-shock-induced resistance (HSIR) [1]. Heat shock (HS) reportedly triggers defensive responses against Colletotrichum gloeosporioides (Penz) Sacc. in strawberry [2], as well as against Botrytis cinerea Pers. (Bc) in melon [1] and cucumber [3]. Furthermore, HS-treated plants accumulated salicylic acid (SA) [1], the primary signaling molecule in systemic acquired resistance (SAR), which plays a role in the initial activation of the heat shock response (HSR) by inducing higher levels of heat shock protein 70 (Hsp70) $[4,5]$. In the present study, we focused on HSIR by studying the regulation of HSR by heat shock transcription factors (Hsfs).

Upon exposure of an organism to heat stress, Hsfs activate gene expression of heat shock proteins (Hsps) by binding the heat shock element (HSE) in the promoter DNA sequence of the corresponding gene [6-8]. HSEs are trinucleotide core sequences, $5^{\prime}-$ nGAAn- $3^{\prime}$ or $5^{\prime}$-nTTCn-3', in alternating 
orientation, separated by two nucleotides [9]. Plants have several homologous Hsfs classified as A, B, and C subfamilies [10]. Tomato has eleven A-, three B-, and one C-class Hsfs [10,11] among which HsfA2 and HsfB1 are heat-stress-inducible proteins themselves [12]. HsfA1 is a master regulator that interacts with $\mathrm{HsfA} 2$ and $\mathrm{HsfB} 1$ to regulate gene expression in response to heat stress [13]. According to Hahn et al. [14], the formation of the HsfA1/HsfA2 super activator complex is responsible for enhancing the expression of Hsps in tomato cell suspension cultures. Under normal conditions, Hsp90 and Hsp70 bind HsfA1, thereby inactivating HsfA1. In contrast, under HS, the complex dissociates, and free HsfA1 enters the nucleus, where it binds HsfA2 to form a super-activator complex that regulates gene expression by binding HSEs located in the upstream regions of genes that are essential for survival under heat stress [14].

Certain stress-related genes with HSEs regulated by Hsfs have been reported. For instance, Storozhenko et al. [15] reported that HsfB1 from a cloned tomato bound the HSE of ascorbate peroxidase (apx) 1 gene and activated its transcription under HS in Arabidopsis. Similarly, an apx bearing a similar HSE motif was also upregulated after exposure of rice seedlings to $42{ }^{\circ} \mathrm{C}$ [16]. Moreover, HsfB1 regulated the expression of defensin-like protein 16 (Pdf1.2a) gene and pathogen resistance in Arabidopsis [17]. These results suggest that the transcription of pathogenesis-related (PR) genes is regulated by Hsfs and that Hsfs are involved in defense responses.

Inhibitors of Hsps and Hsfs have been used to investigate the role of Hsfs in the activation of gene expression after HST. For example, geldanamycin (GDA; NSC 122750) was applied for suppressing the Hsp90 chaperone ATPase cycle in eukaryotic cells by binding the ATP-binding site of the N-terminal domain of Hsp90 [18]. Similarly, the application of GDA on leaves of heat-treated tomato induced accumulation of HsfA2 [19]. Further, pretreatment of tomato cell cultures with GDA before HS enhanced the endogenous levels of HsfA2 and HsfB1, relative to the control treatment [14].

In another case, Hsfs-HSE binding was hindered by KRIBB11 (N2-(1H-indazole-5-yl)-N6methyl-3-nitropyridine-2,6-diamine; KB), the only known transcription factor inhibitor that binds directly to HSF1, a transcription factor that regulates Hsps in human cancer cells [20]. KB showed a maximal inhibitory concentration $\left(\mathrm{IC}_{50}\right)$ of $1.2 \mu \mathrm{M}$ in an Hsps transcription inhibition assay [21]. Induction of Hsp70 was blocked in human colon cancer 116 cells through inhibition of HSF1, thereby completely suppressing the expression of Hsp70 when cells were exposed to HS in the presence of KB. The ability to suppress Hsp70 upon HS exposure suggested that KB might be successfully applied to suppress HSIR.

Based on the foregoing discussion, we hypothesized that if Hsfs are involved in the activation of HSIR, the inhibition of Hsp90 will release HsfA1 and induction of $H s f A 2$ and $H s f B 1$, as well as induction of PR genes, will follow. On the other hand, inhibition of Hsfs will suppress the enhanced expression of PR genes, as well as disease resistance after HS. Moreover, Hsfs gene expression should be upregulated earlier than that of PR gene and the induction of disease resistance.

The objective of this study was to assess the role of Hsfs in the regulation of HSIR. Tomato PR protein 1a2 (PR1a2) and PR protein 1b1 (PR1b1) were chosen as resistance marker genes, because of their distinctive characteristics. An earlier study showed that tomato PR1a2 and PR1b1 genes were upregulated by different modes of action: Upon infection by tobacco mosaic virus, the PR1b1 gene is strongly activated locally in tissues undergoing the hypersensitive response, but not systemically in uninoculated tissues [22]. In addition, wounding was shown to induce PR1b1 expression and wound-induced resistance (WIR) against Pseudomonas syringae pv. tomato (Okabe) Young et al. (Pst) [23], suggesting that PR1b1 tended to be expressed after physical damage via jasmonic acid and ethylene pathway, whereas PR1a2 is positively activated by reactive oxygen species [24], independently from ethylene [22]. Gene expression profile of PR1a2 and PR1b1, SA accumulation, as well as the appearance of resistance against Pst after HS treatment (HST) were evaluated. In addition, we studied the time-course of the expression of Hsf genes and the existence of HSEs in the upstream area of PR genes. GDA and KB were applied to provide evidence for the regulation of HSIR via Hsfs. 


\section{Materials and Methods}

\subsection{Growth and Maintenance of Pathogens and Plant Materials}

Cultures of Pst strain MAFF302666 with pathogenicity of bacterial speck leading to straight-edged brown spots or circular spots with yellow haloes were obtained from the culture collection of the Genetic Resources Center, National Agriculture and Food Research Organization, Tsukuba, Japan. The stock Pst culture was stored in glycerol solution at $-80^{\circ} \mathrm{C}$. For the experiments designed, the culture was maintained on King's B agar slant at $4{ }^{\circ} \mathrm{C}$ and subcultured every four weeks. Pathogenicity of Pst was confirmed by challenge inoculation prior to the experiment. Plants of the tomato cultivar Natsunokoma were grown in soil (Super Mix A; Sakata Co., Ltd., Yokohama, Kanagawa, Japan) at room temperature under a 16:8 h (light: dark) regime, until the second true leaf was fully expanded. Square plastic propagation liner tray arranged in a $2 \times 2$ cell configuration (4 plant/replication) or in a $3 \times 2$ cell configuration ( 6 plants/replication) was used. For partial treatment, plants were grown in individual pots. Plants with abnormal leaves were excluded.

\subsection{Pathogen Inoculation}

Pst cultures were grown overnight at $28^{\circ} \mathrm{C}$ in King's B broth in a shaker (BioShaker BR-13FP; Taitec Co., Ltd., Koshigaya, Saitama, Japan). Next, $10 \mathrm{~mL}$ of each culture was pelleted by centrifuging at $3200 \times g$ for $20 \mathrm{~min}$ and resuspended in $500 \mu \mathrm{L}$ of $10 \mathrm{mM} \mathrm{MgCl}{ }_{2}$ (Nacalai Tesque, Nakagyo, Kyoto, Japan). Cell concentration was measured by determining optical density at $600 \mathrm{~nm}$ using the GeneQuant Pro DNA/RNA Calculator (Amersham Biosciences, Little Chalfont, BKM, UK). These Pst cultures were diluted to $2 \times 10^{7}$ colony-forming units $/ \mathrm{mL}$ in inoculation buffer containing $10 \mathrm{mM}$ $\mathrm{MgCl}_{2}$ plus $200 \mu \mathrm{L} / \mathrm{L}$ Silwett-L77 (Momentive Performance Materials Inc., Waterford, NY, USA). For whole plant treatment, seedlings were inoculated by dipping upside down into the bacterial suspension at different times after HST. For partial treatment, only the first leaf was inoculated in the same manner. Plants dipped into inoculation buffer were used as mock. Then, mock and inoculated plants were separated for incubation in different growth chambers and maintained under the same conditions described above. Disease severity was estimated by the extent of leaf area showing a lesion at 3 days after inoculation according to the following scale: Rank 0 , without injuries; rank 1, less than $10 \%$; rank 2 , from $10 \%$ to $20 \%$; rank 3 , from $20 \%$ to $40 \%$; and rank 4 , above $40 \%$ of leaf tissue affected. Disease index (DI) was calculated as follows: DI $=[\Sigma(\mathrm{n} \times \mathrm{v}) / \mathrm{N} \times \mathrm{Z}]$, where $\mathrm{n}$ is the lesion score as ranked, $\mathrm{v}$ is the number of samples in the score category, $\mathrm{N}$ is the highest score value, and $\mathrm{Z}$ is the total number of samples. The experiment was repeated thrice; DI data shown are means of both first and second leaves from three plants per replicate.

\subsection{Heat Shock, GDA, and KB Treatments}

Whole seedlings or only the first leaf of tomato seedlings at the second-leaf stage, were dipped upside down into water at $45^{\circ} \mathrm{C}$ for $2 \mathrm{~min}$ as described by Sato et al. [25] (Heat shock treatment, HST). Non-treated (NT) plants were used as negative controls. GDA (Tokyo Chemical Industry Co., Ltd., Chuo, Tokyo, Japan) and KB (Tocris Bioscience, Bristol, BRS, UK) were dissolved into dimethyl sulfoxide (DMSO) at 10 and $20 \mathrm{mM}$, respectively and diluted by ion exchange water up to the desired concentration. In addition, DMSO (Nacalai Tesque, Nakagyo, Kyoto, Japan) was diluted to $0.1 \%(v / v)$. GDA and KB were applied manually by foliar spray of $2.5 \mathrm{ml}$ solution each plant using a spray bottle. $\mathrm{KB}$ was applied three times on the leaves at 6, 12, and $18 \mathrm{~h}$ after HST. Mock plants treated with DMSO were used as negative controls. 


\subsection{Gene-Expression Analysis}

For time-course sampling, total RNA was isolated from the first leaf at different time intervals $(3,6,12,24,48$, or $72 \mathrm{~h}$ after HST) using Sepasol-RNA I (Nacalai Tesque, Nakagyo, Kyoto, Japan), following manufacturer instructions. Thereafter, mRNA was reverse transcribed using the Prime Script RT Reagent Kit (Takara Bio Inc., Kusatsu, Shiga, Japan). The synthesized first strand cDNA was used as a template for quantitative real-time polymerase chain reaction (qPCR) analysis. The reaction was performed using the KOD SYBR qPCR Mix (TOYOBO, Kita, Osaka, Japan) on a CFX Connect Real-Time PCR system (Bio-Rad, Hercules, CA, USA) according to the user's manual. The following cycling condition was used for qPCR reaction: Initial denaturation at $98^{\circ} \mathrm{C}$ for $120 \mathrm{~s}$, then 40 cycles of $98^{\circ} \mathrm{C}$ for $10 \mathrm{~s}, 60^{\circ} \mathrm{C}$ for $15 \mathrm{~s}$, and $68^{\circ} \mathrm{C}$ for $30 \mathrm{~s}$. The gene-expression levels in each sample were normalized to those of glyceraldehyde-3-phosphate dehydrogenase (GAPDH) gene. Gene-specific primers used for qPCR were designed using the National Center for Biotechnology Information (NCBI; Bethesda, MD, USA) program Primer Blast, with the parameters set to create a product of 200-500 base pairs (bp) within the region of the target mRNA (Table 1). In a preliminary experiment, no significant changes were observed in the expression levels of $P R 1 b 1$ and $H s f A 2$ from 0 to $3 \mathrm{~h}$ after HST (Supplementary Figure S1). In partial-treatment tests, only the first leaf of tomato was treated by HS or inoculation, and gene-expression levels in treated (first leaf) and untreated (second leaf) plants were independently analyzed using the protocol described above. The second leaves of untreated plants were also analyzed as references. Three technical replicates of qPCR were performed for each biological replicate.

\subsection{Measurement of SA and Salicylic Acid b-D-Glucoside (SAG) Levels}

The extraction and measurement of SA and salicylic acid b-D-glucoside (SAG) by liquid chromatography-tandem mass spectrometry (LC-MS/MS) was conducted as previously described by Widiastuti et al. [26]. The first leaf from three plants was mixed for one analysis. Each of three replications consisted of three plants. A standard methanolic solution was prepared by diluting SA (Kanto Chemical Inc., Chuo, Tokyo, Japan) and SAG (Santa Cruz Biotechnology Inc., Dallas, TX, USA).

\subsection{Identification of HSEs in the Upstream Regions of PR Genes}

Sequences of PR1a2, PR1b1, Chitinase 3 (Chi3), Chitinase 9 (Chi9), Glucanase A (GluA), and Glucanase B (GluB) genes were retrieved from the tomato genome (assembly SL2.50) stored in the NCBI Reference Sequence Database. The upstream regions of tested PR genes were investigated for the existence of HSE-like sequences by manual annotation.

\subsection{Statistical Analysis}

The Tukey-Kramer test was performed for experiments involving inoculation. For SA and SAG determination, significant differences between NT and HST were evaluated by a two-tailed $t$-test at each sampling time-point. Arcsine-transformed values were applied for statistical analysis when data were distorted from the normal distribution. All analyses were performed by Statistical Analysis System (SAS) University Edition software (version: university.cny.sas.com@sas: university-6p.2/6p.2.688de4662a09-1-1; SAS Institute Inc., Cary, NC, USA). 
Table 1. Primers used to amplify pathogenesis-related (PR), heat shock transcription factors (Hsfs), and glyceraldehyde-3-phosphate dehydrogenase (GAPDH) genes from tomato leaves.

\begin{tabular}{|c|c|c|c|c|c|}
\hline Target Gene & Location & Accession Number & Properties & Primer Name & Sequence $\left(5^{\prime}\right.$ to $\left.3^{\prime}\right)$ \\
\hline \multirow{2}{*}{ PR1a2 } & \multirow{2}{*}{$\operatorname{chr} 9$} & \multirow{2}{*}{ NM_001321040.1 } & \multirow{2}{*}{ Pathogenesis-related leaf protein 4 Acidic } & SLPR1a2 F & TGTTACTTATGACTTGTCTCATGGT \\
\hline & & & & SLPR1a2 R & CGACCCAATTGCCTACAGGA \\
\hline \multirow{2}{*}{ PR1b1 } & \multirow{2}{*}{ unplaced scaffold } & \multirow{2}{*}{ NM_001247385.2 } & \multirow{2}{*}{ Pathogenesis-related leaf protein 6 Basic } & SLPR1b1 F & ACATCTCATTGTTACTCACTTGTCT \\
\hline & & & & SLPR1b1 R & GACGTTGTCCGATCCAGTT \\
\hline \multirow{2}{*}{ GluA } & \multirow{2}{*}{ chr 1} & \multirow{2}{*}{ NM_001247869.2 } & \multirow{2}{*}{ Glucan endo-1,3-beta-D-glucosidase Acidic } & SLGluA F & GGTCTCAACCGCGACATATT \\
\hline & & & & SLGluA R & CACAAGGGCATCGAAAAGAT \\
\hline \multirow{2}{*}{ GluB } & \multirow{2}{*}{ chr 1} & \multirow{2}{*}{ NM_001247876.2 } & \multirow{2}{*}{$\beta$-1,3-glucanases Basic } & SLGluB F & TCTTGCCCCATTTCAAGTTC \\
\hline & & & & SLGluB R & TGCACGTGTATCCCTCAAAA \\
\hline \multirow{2}{*}{ Chi3 } & \multirow{2}{*}{$\operatorname{chr} 2$} & \multirow{2}{*}{ NM_001247475.2 } & \multirow{2}{*}{ Class III endochitinase Acidic } & SLChi3 F & TGCAGGAACATTCACTGGAG \\
\hline & & & & SLChi3 R & TAACGTTGTGGCATGATGGT \\
\hline \multirow{2}{*}{ Chi9 } & \multirow{2}{*}{ chr 10} & \multirow{2}{*}{ NM_001247474.2 } & \multirow{2}{*}{ Class I chitinase Basic } & SLChi9 F & СТCCAATGGCTCTTCCACAT \\
\hline & & & & SLChi9 R & GAAATTGCTGCTTTCCTTGC \\
\hline \multirow{2}{*}{ HsfA2 } & \multirow{2}{*}{$\operatorname{chr} 8$} & \multirow{2}{*}{ XM_010326728.2 } & \multirow{2}{*}{ Heat shock transcription factor A2 } & SLHsfA2 F & GCGAATGGAGGTTTTCTGGG \\
\hline & & & & SLHsfA2 R & GTCACAACAGAATCCGGCCT \\
\hline \multirow{2}{*}{$H s f B 1$} & \multirow{2}{*}{ chr 2} & \multirow{2}{*}{ NM_001321450.1 } & \multirow{2}{*}{ Heat shock transcription factor B1 } & SLHsfB1 F & CTATACGCCGTCGGAAGACC \\
\hline & & & & SLHsfB1 R & TACCACGTCCACCACAAGTC \\
\hline \multirow{2}{*}{ GAPDH } & \multirow{2}{*}{$\operatorname{chr} 5$} & \multirow{2}{*}{ NM_001279325.2 } & \multirow{2}{*}{ Glyceraldehyde-3-phosphate dehydrogenase } & SLGAPDH F & GGTTTGGCATTGTTGAGGGTC \\
\hline & & & & SLGAPDH R & TCGACAACGGAGACATCAGC \\
\hline
\end{tabular}




\section{Results and Discussion}

\subsection{Changes in Resistance Induced by HST}

There was no significant difference in disease severity between mock (DI 1.00) and plants inoculated at $3 \mathrm{~h}$ (DI 1.00) and $6 \mathrm{~h}$ (DI 0.97) after HST. Disease severity significantly reduced in plants inoculated at 12 and $24 \mathrm{~h}$ after HST to DI 0.35 and 0.46 , respectively, relative to mock plants. Thereafter, disease severity increased to DI 0.81 at $48 \mathrm{~h}$ and decreased again to DI 0.64 at $72 \mathrm{~h}$ after HST (Figure 1a). Significant reduction in disease severity was observed in the first leaves, but not in the second leaves when only the first leaves were treated with HS (Figure 1b,c).

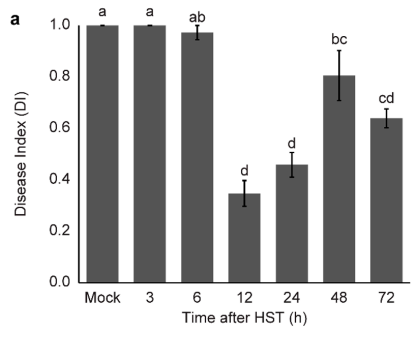

(a)

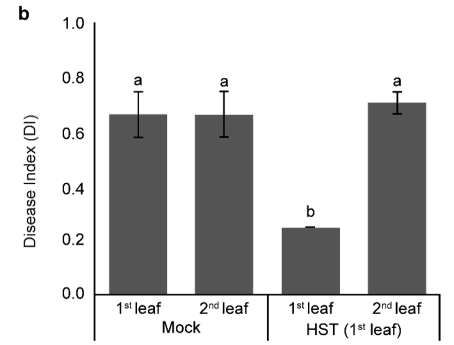

(b)

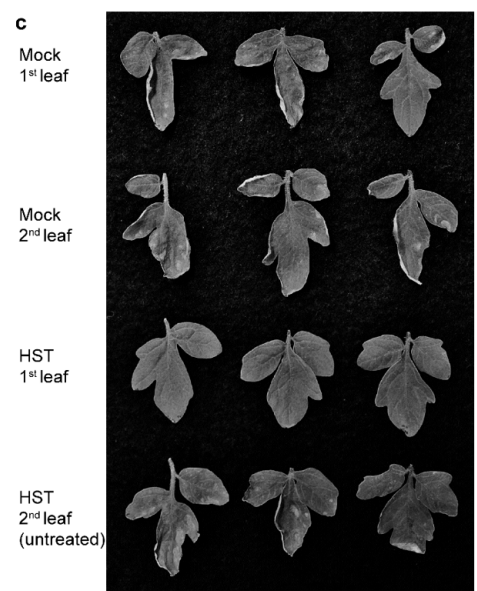

(c)

Figure 1. Effect of Pst inoculation-timing on disease severity. (a) NT: No HST followed by Pst challenge by inoculation at $3,6,12,24,48$, or $72 \mathrm{~h}$ after HST $\left(45^{\circ} \mathrm{C}, 2 \mathrm{~min}\right)$. (b) Partial HST tests, only the first leaf of tomato plants was treated by HS, followed by inoculation on both first and second leaves at $24 \mathrm{~h}$ after HST. (c) bacterial speck symptom caused by Pst. Vertical bars indicate the standard error of the mean $(n=3)$. Different letters indicate significant differences between treatments, based on Tukey's test, $p<0.05$.

Disease severity was reduced in plants under HST compared to mock plants when inoculation was done $12 \mathrm{~h}$ after HST. However, the effect was not systemic. Induction of the defense response by HST was observed previously in melon [1]. HST at $50{ }^{\circ} \mathrm{C}$ for $20 \mathrm{~s}$ resulted in the maximum reduction of $B c$ symptoms in plants inoculated immediately after HST and $24 \mathrm{~h}$ after HST. On the other hand, when inoculation was performed more than $24 \mathrm{~h}$ after HST, plants were not protected against the pathogen. This result indicated that a similar mechanism mediates HSIR against $B c$ in melon plants and against Pst in tomato plants. On the other hand, HST reportedly activated systemic induction of the defense response, which was different to the result observed in tomato under the current experimental conditions [23]. Hot water dipping of the first leaves $\left(50{ }^{\circ} \mathrm{C}\right.$ for $\left.20 \mathrm{~s}\right)$ of melon seedlings significantly reduced $B c$ lesion diameter on detached untreated leaves. It is unclear whether the experimental conditions or the difference in plant species was the main reason for failure to induce systemic resistance in tomato. Nevertheless, the reduction in Pst lesions suggested that the defense response against Pst in tomato was effectively induced by HST.

\subsection{PR1a2, PR1b1, HsfA2, and HsfB1 Expression Profiles and SA Accumulation}

Gene expression analysis showed that PR1a2 (Figure 2a) and PR1b1 (Figure 2b) upregulation started at $12 \mathrm{~h}$ after HST and peaked at $24 \mathrm{~h}$ after HST, followed by a decline at $48 \mathrm{~h}$ after HST; whereas PR1a2 and PR1b1 gene expression was not detectable in NT. Furthermore, upregulation of PR1a2 and PR1b1 were not observed in the second leaf, which was not treated in partial HS experiments 
(Figure 3a,b). On the other hand, PR1a2, but not PR1b1, was upregulated in the second leaf at $24 \mathrm{~h}$ after partial inoculation (Figure 3c,d). Both PR1a2 and $P R 1 b 1$ were upregulated at $72 \mathrm{~h}$ after HST in $P s t$-inoculated plants at $24 \mathrm{~h}$ after HST to a similar extent as HST-untreated Pst-inoculated plants, while plants subjected to HST only did not show induced gene expression (Figure 3e,f). The upregulation of both $H s f A 2$ and HsfB1 peaked at $6 \mathrm{~h}$ after HST (Figure 4a,b). Although HsfA2 was upregulated at $3 \mathrm{~h}$ after HST and peaked at $6 \mathrm{~h}$ after HST, expression declined starting at $12 \mathrm{~h}$ after HST and until the end of the experimental period. The expression pattern of $H s f B 1$ was different from that of $H s f A 2$, as it gradually decreased from 12 to $24 \mathrm{~h}$ after HST, but still retained a higher expression level than that in NT. SA accumulated significantly at $12 \mathrm{~h}$ after HST, but then constantly decreased from 24 to $48 \mathrm{~h}$ after HST (Figure 5a). In turn, SAG started to accumulate significantly at $48 \mathrm{~h}$ after HST, when SA accumulation had already ceased (Figure $5 b$ ).
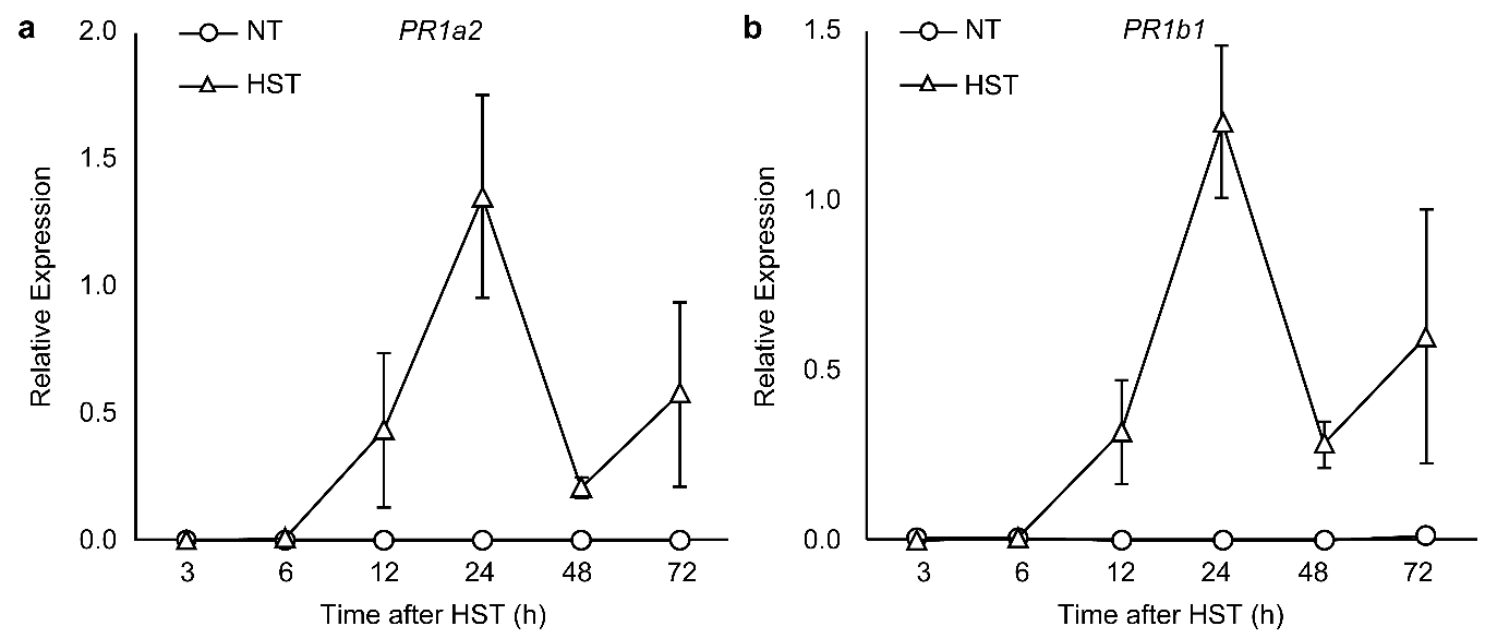

Figure 2. Changes in (a) PR1a2, and (b) PR1b1 expression levels in the tomato cultivar Natsunokoma. Gene expression levels in the first leaf at 3, 6, 12, 24, 48, or $72 \mathrm{~h}$ after HST ( $45^{\circ} \mathrm{C}, 2 \mathrm{~min}$ ) were quantified by qPCR and normalized to GAPDH expression. Vertical bars indicate the standard error of the mean $(n=4)$.

Widiastuti et al. $[1,26]$ showed that peroxidase and chitinase genes were upregulated at $12 \mathrm{~h}$ after HST in melon plants, whereas in cucumber, the peroxidase gene was upregulated at $24 \mathrm{~h}$ after HST [3]. The results in tomato leaves were consistent with those in melon and cucumber, although experimental conditions differed. Transient expression profiles of PR1a2 and PR1b1 (Figure 2) corresponding with the appearance of induced resistance against Pst (Figure 1a) suggested that the expression of these genes was triggered as part of the HSIR pathway of plant response to heat stress. However, the expression was not systemic, thereby confirming the difference between partial-HST and Pst challenge. When plants were inoculated with Pst, systemic expression of PR1a2 was observed. This result indicated that the defense response triggered by HS was different from that triggered by pathogen infection. Stout et al. [27] observed that partial inoculation induced SAR in tomato. The failure of systemic induction of disease resistance and PR gene expression showed that HST could not activate SAR after $24 \mathrm{~h}$.

The expression pattern of $H s f A 2$ (Figure 4a) was different from that of $H s f B 1$ (Figure 4b). According to Hahn et al. [14], the interaction of HsfB1 with Hsp70/90 under normal conditions maintains HsfB1 production at a low level, due to rapid degradation, thus, explaining the low expression of $H s f B 1$ over time under NT, which was not observed for HsfA2. These results suggest the possibility that Hsfs might be activated prior to SA accumulation or PR gene expression in response to HS. Hence, Hsfs might be the triggering molecules that induce defense responses following HST in addition to SAR. 

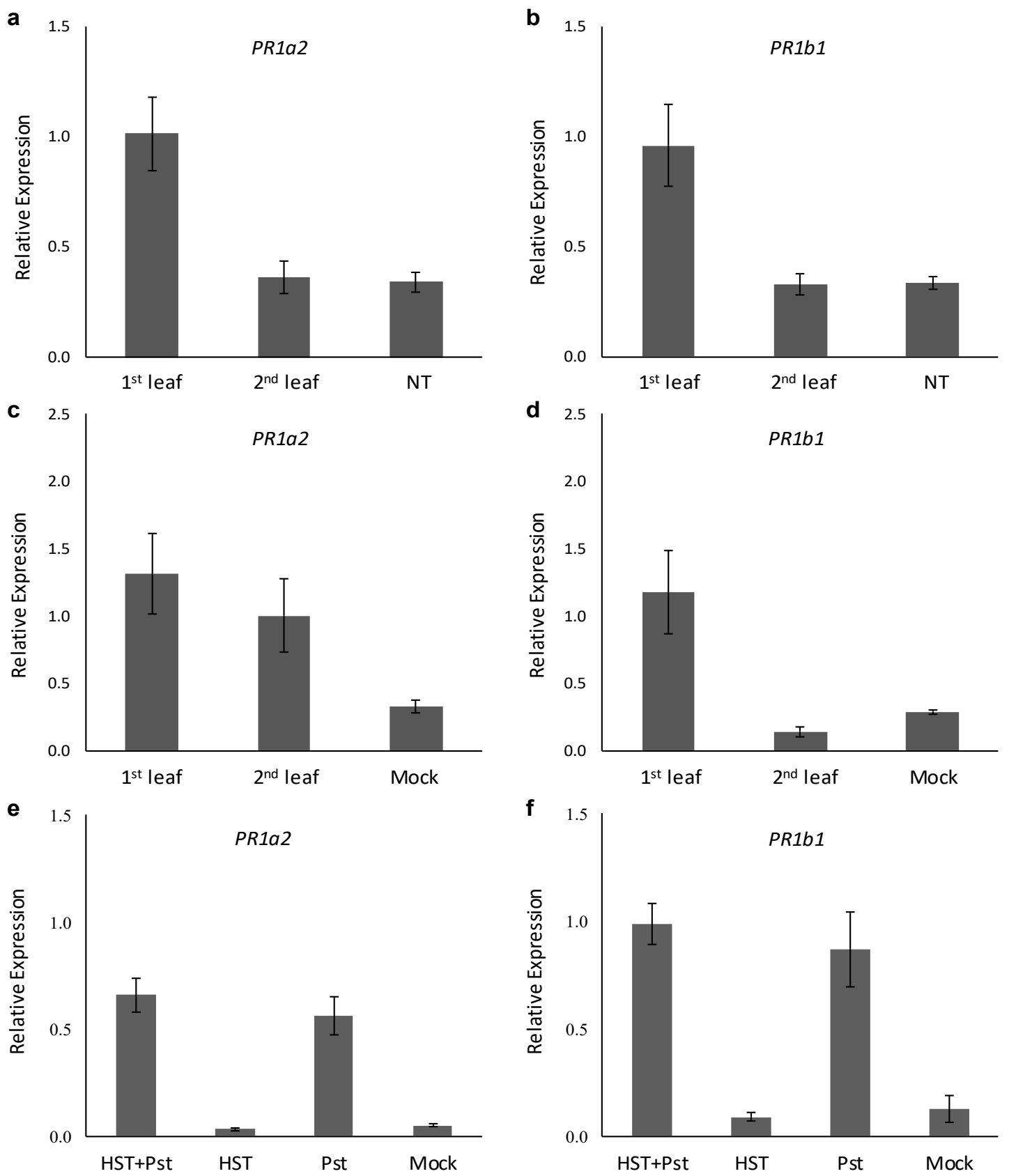

Figure 3. Relative expression levels of PR1a2 and PR1b1 in the leaves of the tomato cultivar Natsunokoma after partial treatment by HS, Pst inoculation or combined HS + Pst inoculation. Only the first leaf was subjected to HST at $45^{\circ} \mathrm{C}$ for $2 \mathrm{~min}(\mathbf{a}, \mathbf{b})$ or dipped into Pst solution $(\mathbf{c}, \mathbf{d})$. Thereafter, total RNA from the first and second leaf was extracted at $24 \mathrm{~h}$ after HST or Pst inoculation. In combined treatment (e,f), Pst was inoculated at $24 \mathrm{~h}$ after HST. Total RNA from the first leaf was extracted at $48 \mathrm{~h}$ after Pst inoculation, which was $72 \mathrm{~h}$ after HST. Gene-expression levels were quantified by qPCR and normalized to GAPDH expression. Vertical bars indicate the standard error of the mean $(n=6)$. 

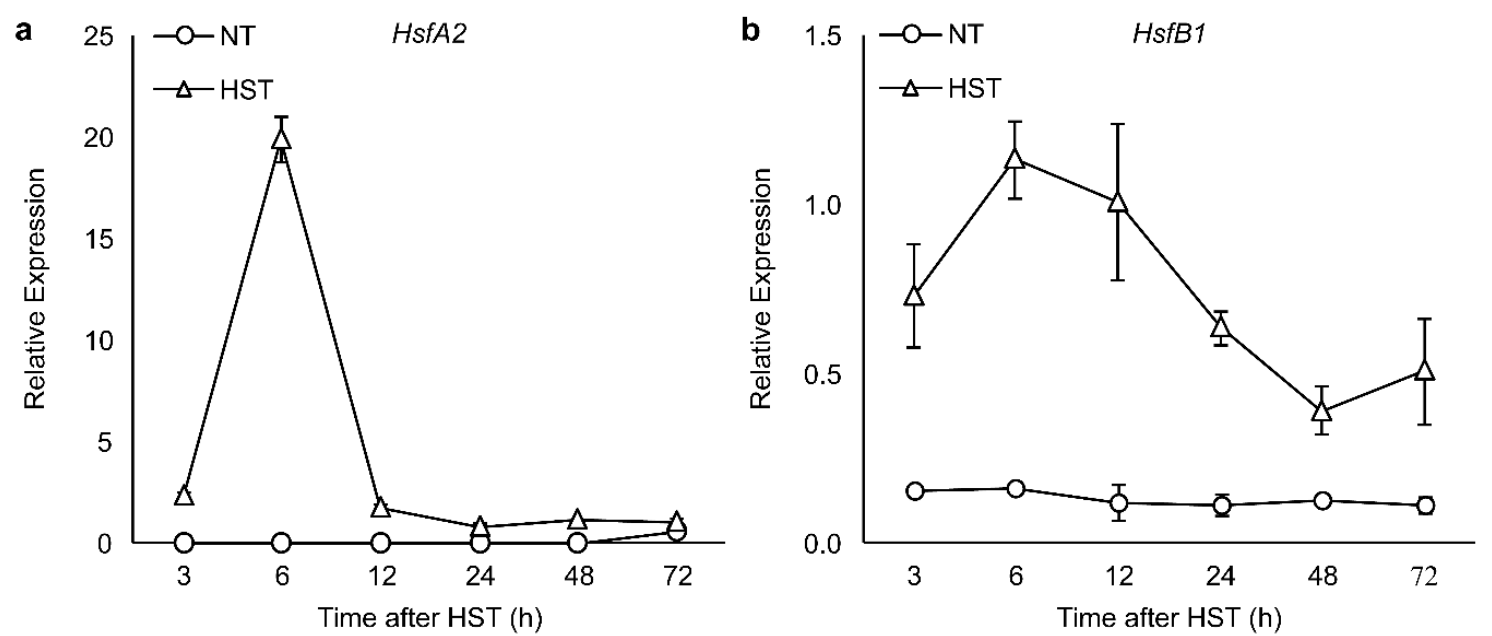

Figure 4. Changes in the relative expression level of (a) $H s f A 2$ and (b) $H s f B 1$. Gene expression levels in the first leaf at $3,6,12,24,48$, or $72 \mathrm{~h}$ after $\mathrm{HST}\left(45^{\circ} \mathrm{C}, 2 \mathrm{~min}\right)$ were quantified by qPCR and normalized to $G A P D H$ expression. Vertical bars indicate the standard error of the mean $(n=4)$.

a

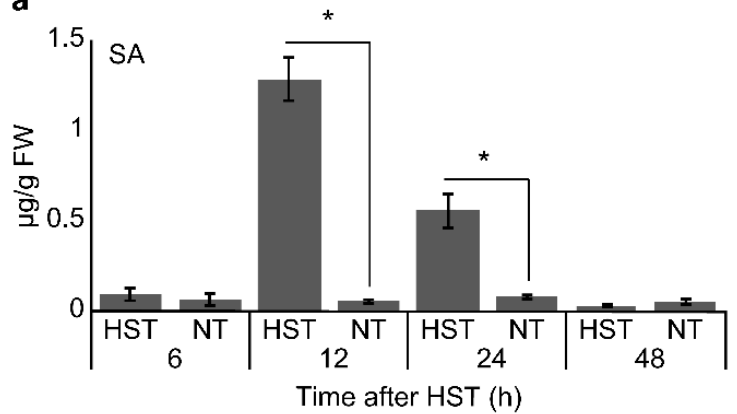

b

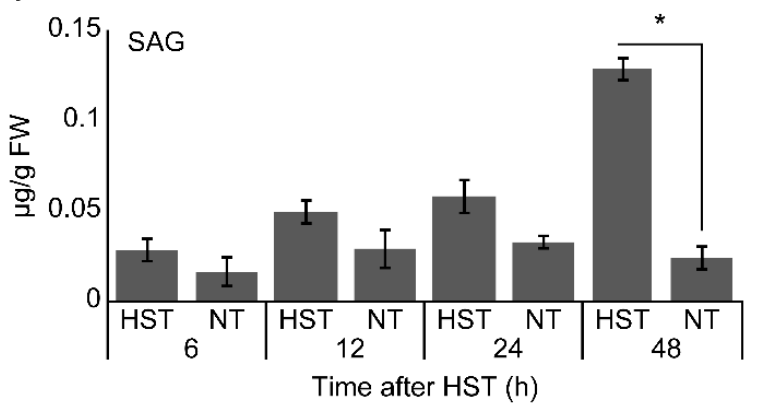

Figure 5. Accumulation of (a) salicylic acid (SA) and (b) salicylic acid b-D-glucoside (SAG) at 6, 12, 24 and $48 \mathrm{~h}$ after HST. Vertical bars indicate the standard error of the mean $(n=3)$. Significant differences between groups (indicated by asterisks) were obtained from performing two-tailed $t$-tests, $p<0.05$. FW, fresh weight.

SA is involved in providing systemic immunity to pathogens [28-30]. Transient accumulation of SA was considered to cause the failure of systemic resistance. In case of pathogen infection or chemical activator treatment, an elicitor derived from the pathogen or a chemical derivative often remains around the infected part and acts as a signaling compound persistently. In contrast, the duration of HSIR was shorter than that of SAR, because no compound was applied to plants externally in conjunction with HST.

SA plays a different role in response to HS, from the one it plays on alleviating the damaging effect of high temperature. Exogenous application of SA protects Arabidopsis against heat-induced oxidative damage [31], thus, reducing the adverse effects of heat stress on photosynthesis in wheat [32] and grapevine [33]. Snyman and Cronjé [34] reported that SA assisted the binding of Hsfs to HSEs in the promoter regions of stress genes in tomato. They noted that SA alone had no significant effect on $H s f A 1$ and $H s f B 1$ expression, but potentiated the basal level of $H s f A 1$, followed by accumulation of Hsps in heat-treated plants. Moreover, tomato PR1b1 promoter activity was enhanced by SA [22]. It appears that SA content post-HS did not reach a SAR-inducing concentration; thus, it was unable to induce systemic expression of PR genes, as well as systemic resistance against Pst. Further, it was not clear whether the appearance of local resistance after HST was induced by SA. However, if previous studies on the ability of SA to enhance Hsf-DNA binding are considered, the hypothesis of a direct regulation of locally induced resistance by Hsfs gains strong support. 


\subsection{Identification of HSEs Motifs in the Upstream Regions of Target Genes}

Multiple possible HSE motifs were discovered in the upstream regions up to $2500 \mathrm{bp}$ from the start codon of all tested PR genes. Four possible HSE motifs were found on PR1a2 and Chi9; two motifs on PR1b1, Chi3, and GluA; and one motif on GluB (Figure 6a). As far as we could learn, all tested genes possessed these motifs. At least two HSE motifs are in reverse orientation and perfectly match the requirements for the minimal Hsfs-binding motif $5^{\prime}$-nGAAn-3' or $5^{\prime}$-nTTCn-3' (Figure 6b).

a

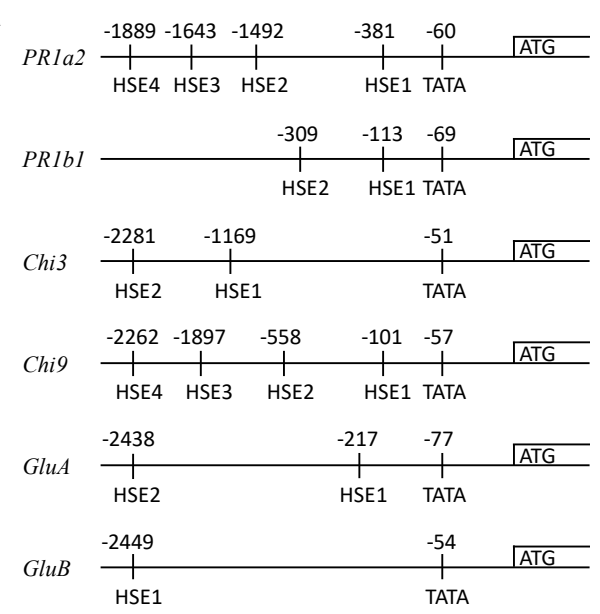

b S1-PR1a2 HSE1 5'- ttatTTAgattGAAttTTCctTTAaaaaagctt - 3'

HSE2 $5^{\prime}$ - ggtaatGGAgaGAAacTTAttTTCttGAAttgc - $3^{\prime}$

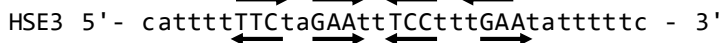

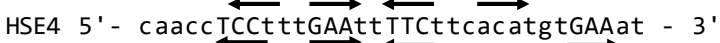

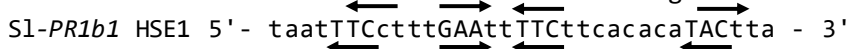

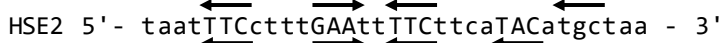
Sl-Chi3 HSE1 5'- ggcctcTTCtaGAAgcaGTAagaTACactcttg - 3' HSE2 $5^{\prime}$ - tTTCtaaacaaGAAatTTCtataataTCAcaac - 3'

S1-Chi9 HSE1 5'- gç્AActaataGAAaaTTCacagTAggtctcca - 3' HSE2 $5^{\prime}$ - atctctaTTCtGAAat TTCg tactcGAAaaTTG - 3' HSE3 $5^{\prime}$ - aataaaTTCatGAAtGAACatagTCAaaaaaa - $3^{\prime}$

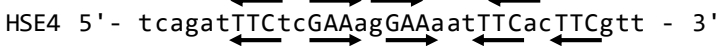

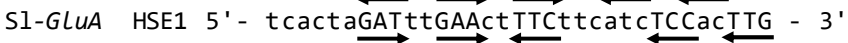
HSE2 $5^{\prime}$ - ataagaTTCtaGAAtTTCagtcataacGTAgga - 3' S1-GLUB HSE1 5'- actaaaCAAatGAAggTTCaatatcTACtatat - 3'

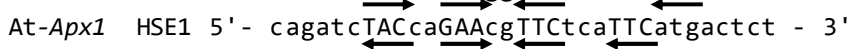

Figure 6. (a) The location of possible heat shock elements (HSEs) in tomato PR genes. The numbers indicate the distance (in bp) from the proximal transcription start site (ATG). TATA represents the TATA box consensus sequence. (b) Comparison of the HSE from tomato PR genes (Sl-) and Arabidopsis apx1 (At-). Sequences matching the nGAAn, the basic 5 bp HSE motif are indicated in uppercase letters. Orientation of the nGAAn-like motifs are indicated by arrows.

The number of HSEs, as well as the distance from the start codon, varied among PR genes. Nevertheless, the expression profiles of PR genes did not change. Nover [35] reported that heat shock inducible genes possessed a functional HSE at a distance of -40 to -400 from the start codon in eukaryotic cells, such as those of Drosophila melanogaster Meigen., humans, Xenopus laevis Daudin., Caenorhabditis elegans Maupas., plants, and Dictyostelium discoideum Raper. Our data showed that PR1a2, PR1b1, Chi9, and GluA fulfilled those criteria. Consistently, Hoffman and Corces [36] demonstrated that cascades of HSE that extend up to -2100 must interact for optimum HS-induced Hsp28 activity in Drosophila. In tomato, PR1b1 with distinct HSE structure has been extensively studied as a major protein responsive to chilling temperature. Exposure of tomato fruits to chilling temperature $\left(2{ }^{\circ} \mathrm{C}\right)$ followed by re-warming of the fruits at $20{ }^{\circ} \mathrm{C}$ led to a several-fold increase in PR1b1 content [37]. This result confirmed that PR1b1 was responsive to changes in temperature. Moreover, the interaction between cloned tomato HsfB1 and the Arabidopsis apx1 promoter confirmed that apx1 HSE was functional as an Hsfs-binding site [15]. Therefore, it is possible that the existence of an HSE in the upstream area contributes to HS-induction of PR genes, although further experimentation is required to confirm that the corresponding HSE in PR genes is recognized by Hsfs.

\subsection{HSP90 and HSF Inhibitor Treatment}

Optimum concentration of GDA required to induce $P R 1 b 1$ gene expression was $10 \mu \mathrm{M}$, while lower or higher concentrations failed to induce it (Figure 7). Upregulation of PR1a2, PR1b1, Chi3, Chi9, GluA, GluB, HsfA2, and HsfB1 after GDA treatment, as well as HST, are shown in Figure 8a, b, c, d, e, f, g, and h, respectively. The most effective concentration of KB to inhibit HSR was 100 $\mu \mathrm{M}$, and the expression level of PR1b1 was reduced to $60.9 \%$ of the level induced by HST (Figure 9). Foliar spray of KB repeated at 6, 12, and $18 \mathrm{~h}$ after HST, successfully suppressed the upregulation 
of all tested PR genes. The expression level of PR1a2, PR1b1, Chi3, Chi9, GluA, and GluB decreased to $30.5 \%, 32.1 \%, 46.2 \%, 62.3 \%, 36.4 \%$, and $54.2 \%$, respectively (Figure 10a-f), upon KB treatment. Conversely, the expression levels of $H s f A 2$ and $H s f B 1$ were increased by $39.9 \%$ (Figure $10 \mathrm{~g}$ ) and $25.1 \%$ (Figure 10h), respectively. The effect of KB-induced inhibition of Hsfs on disease resistance against Pst was confirmed by challenge inoculation. HST alone caused a significant reduction in disease severity, while the results from HST combined with KB were similar to those of DMSO (Figure 11).

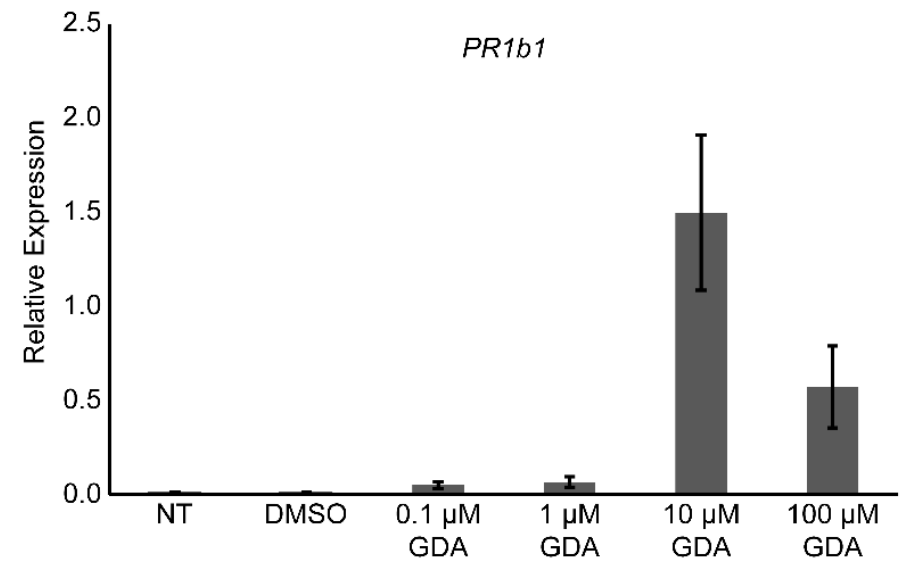

Figure 7. The relative expression level of $P R 1 b 1$ in the leaves of the tomato cultivar Natsunokoma at $24 \mathrm{~h}$ after geldanamycin (GDA) treatment. Different GDA concentrations $(0.1,1,10$, and $100 \mu \mathrm{M})$ and $0.1 \%(v / v)$ dimethyl sulfoxide (DMSO) were applied by foliar spray. Gene expression levels were quantified by qPCR and normalized to GAPDH expression. Vertical bars indicate the standard error of the mean $(n=4)$.

Induction of gene expression was lower in GDA-treated plants, compared to HST plants, except for GluA and Chi9. Under HS, HsfA1 is released from HSP90 complexes; thus, a high amount of free HsfA1 can bind the HSE to induce downstream gene transcription. On the other hand, the mode of action of GDA is to prevent Hsp90 binding the newly synthesized HsfA1 by substrate competition; thus, GDA cannot release HsfA1 already bound to Hsp90. Therefore, the amount of free HsfA1 is less than that under HST; consequently, downstream gene transcription is also lower.

GDA has been shown to enhance HsfB1 protein production. The amount of HsfB1 protein gradually increased from 3 to $9 \mathrm{~h}$ after incubation of tomato suspension-cell cultures in the presence of $1 \mu \mathrm{M}$ GDA [14]. In addition, Hsp90-silenced tomatoes showed an increased level of HsfA2 protein compared to the leaves transformed with an empty vector [19]. Since Hsp90 regulates the activation of HsfA1 [14], previous results of HsfB1 induction by GDA treatment [14] and HsfA2 upregulation in Hsp90-silenced cells indicated that both HsfA2 and HsfB1 were regulated by HsfA1 [19]. Meanwhile, the application of Hsp90 inhibitor GDA induced the expression of HsfA2, HsfB1, and PR genes (Figure 8), which was found to have an HSE in the upstream gene area (Figure 6). These results suggested that the mechanism that regulates HSR via Hsfs might also operate in the regulation of HSIR. Moreover, data from an analysis of the time-course followed by gene-expression profiles showed that the induction of $H s f A 2$ and $H s f B 1$ preceded the expression of PR genes, which means that either HsfA2 or HsfB1 is likely responsible for the upregulation of PR genes after HST. 

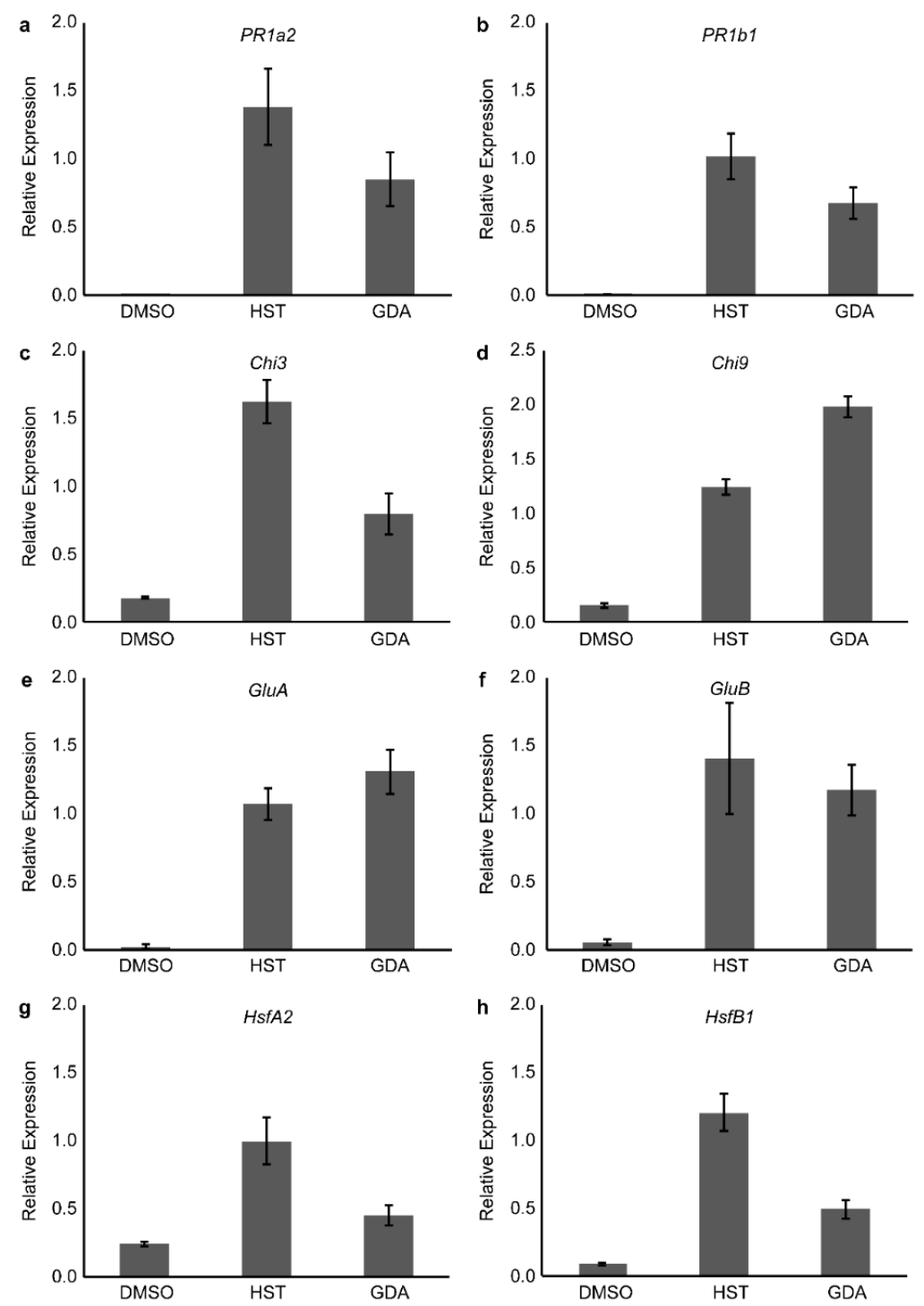

Figure 8. Relative expression level of PR (a-f) and Hsfs (g,h) genes in the leaves of the tomato cultivar Natsunokoma at $24 \mathrm{~h}$ after treatment with DMSO, HST, and GDA. 0.1\% (v/v) DMSO and $10 \mu \mathrm{M}$ GDA were manually applied by foliar spray. Gene expression levels were quantified by qPCR and normalized to GAPDH expression. Vertical bars indicate the standard error of the mean $(n=4)$.

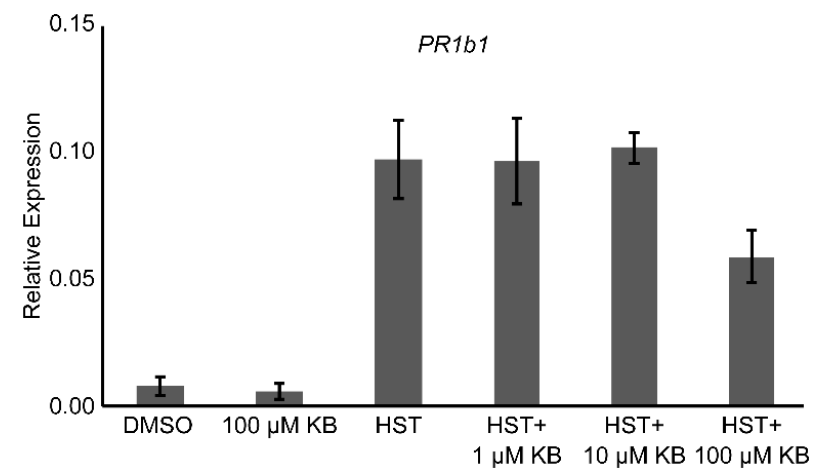

Figure 9. The relative expression level of $P R 1 b 1$ in the leaves of the tomato cultivar Natsunokoma at $24 \mathrm{~h}$ after HST combined with KB. Different KB concentrations $(1,10$, and $100 \mu \mathrm{M})$ were manually applied by foliar spray at $6 \mathrm{~h}$ after HST. Gene expression levels were quantified by qPCR and normalized to GAPDH expression. Vertical bars indicate the standard error of the mean $(n=4)$. 

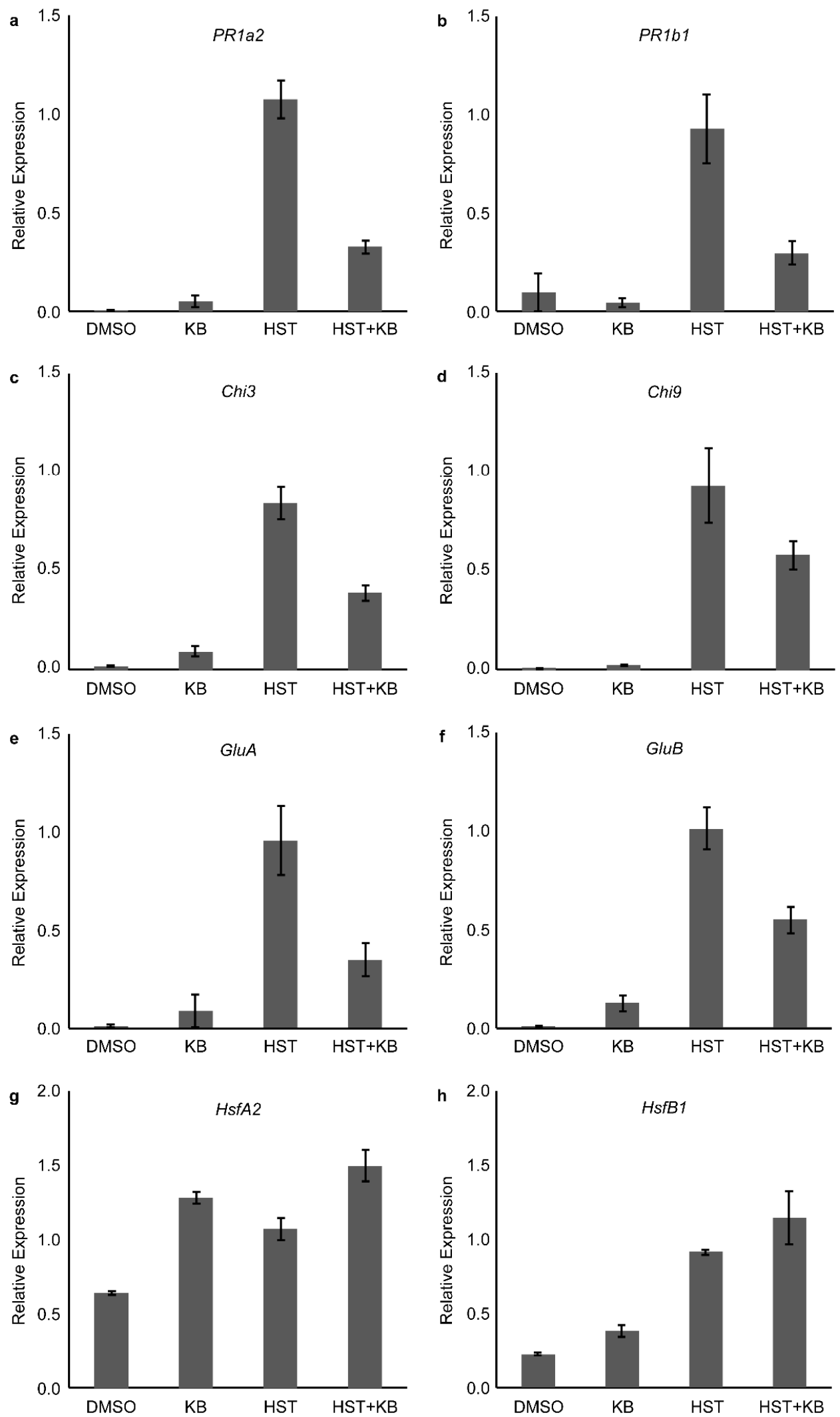

Figure 10. The relative expression level of PR (a-f) and Hsfs $(\mathbf{g}, \mathbf{h})$ genes in the leaves of the tomato cultivar Natsunokoma at $24 \mathrm{~h}$ after HST combined with KB. $100 \mu \mathrm{M}$ of KB was manually applied by foliar spray at 6,12 , and $18 \mathrm{~h}$ after HST. Gene expression levels were quantified by qPCR and normalized to GAPDH expression. Vertical bars indicate the standard error of the mean $(n=6)$. 


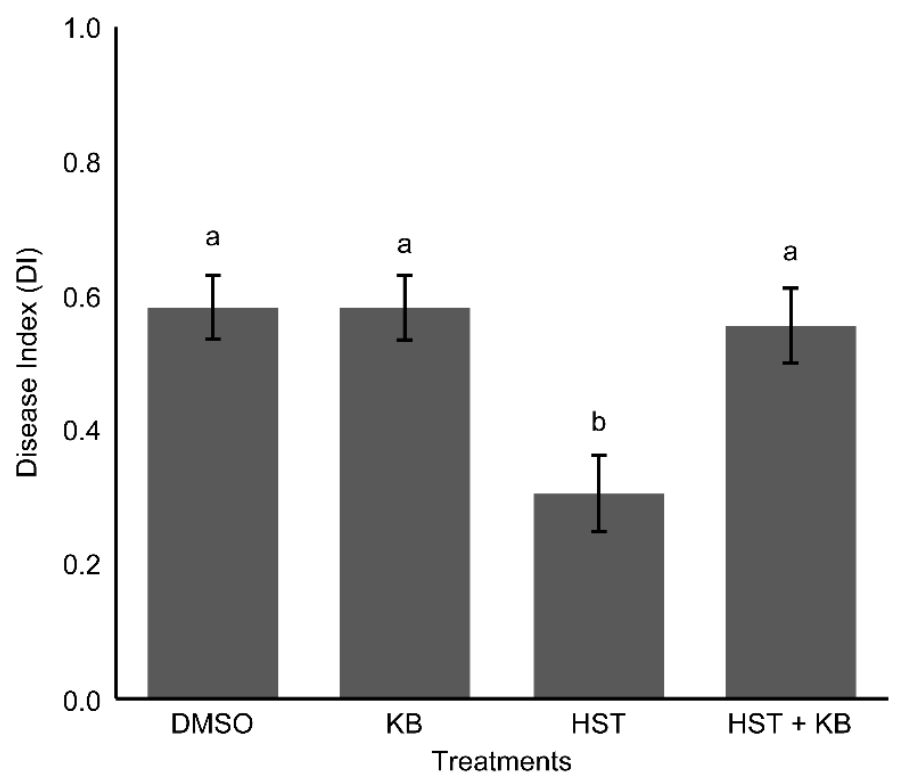

Figure 11. Disease severity upon inoculation of Pst. 1\% DMSO, $100 \mu \mathrm{M} \mathrm{KB}, \mathrm{HST}$, and HST combined with $100 \mu \mathrm{M} \mathrm{KB}$ manually applied by foliar spray at 6,12, and $18 \mathrm{~h}$ after HST. Vertical bars indicate the standard error of the mean $(n=3)$. Different letters indicate significant differences among treatments based on Tukey's test, $p<0.05$.

Upregulation of both, HsfA1 and HsfB1 under the combined HST-KB treatment showed that KB did not affect the master regulator of HSR, HsfA1, which regulates the expression of $H s f A 2$ and $H s f B 1$. On the other hand, the expression of PR genes, as well as the preventive effect of HS against Pst were suppressed under the same treatment. Since PR gene expression was detected following $H s f A 2$ and $H s f B 1$, the suppression of PR genes is likely caused by KB-induced inhibition of HsfA2 or HsfB1.

\section{Conclusions}

A protective effect of HST against pathogen infection was observed in tomato at 12 and $24 \mathrm{~h}$ after HST. The accumulation of SA after HST showed that SAR was involved in HSIR. However, HST failed to induce systemic PR gene expression or systemic resistance against Pst. Local induction of the defense response and PR gene expression following HST demonstrated that a different mechanism was involved. Induced Hsfs gene expression preceded SA accumulation and PR gene upregulation. A schematic representation of our interpretation of the results reported herein is presented in Figure 12. We proposed that Hsfs-mediated HSIR is activated (Figure 12a) before SAR becomes activated (Figure 12b). This hypothesis was substantiated by the results of GDA-induced inhibition of Hsp90 and KB-induced inhibition of Hsfs. PR gene expression was upregulated after HS or GDA treatment, while KB suppressed HS-induced PR gene expression, but not $H s f A 3$ and HsfB1. Overall, these results suggest that Hsfs were responsible for the activation of PR genes, which in turn led to the induction of resistance against $P$ st in tomato leaves.

Further, if Hsfs were also induced by infection, they can be proposed as a universal trigger for the activation of a defense response. Finally, the possibility that Hsfs function as triggering molecules in HSIR provides new insights into the molecular mechanisms of plant defense systems against pathogens, as well as the opportunity to develop new approaches for crop protection. 
HSIR

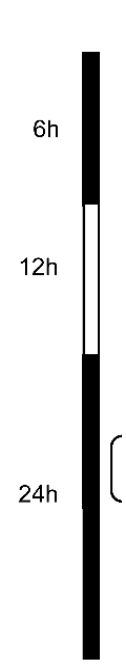

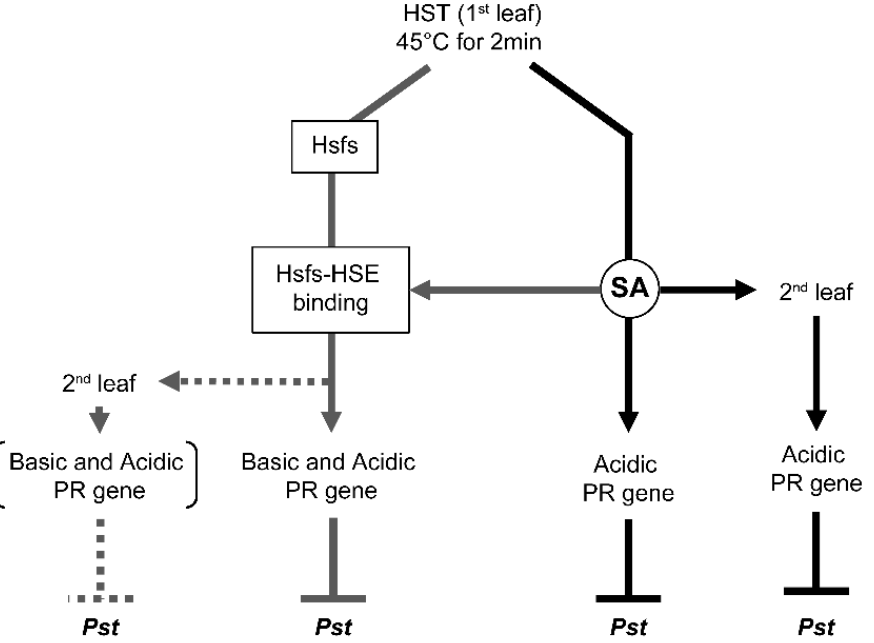

b

\section{SAR}

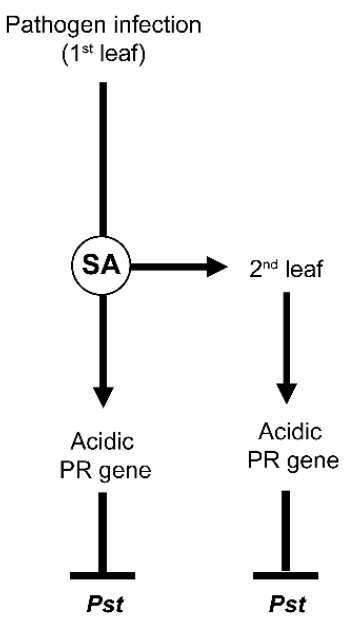

Figure 12. Comparison between HSIR (a) and systemic acquired resistance (SAR) (b). Black lines indicate proved pathways and gray lines indicate proposed pathways as elucidated by the work reported herein. During HSIR, Heat shock induced Hsfs gene expression, followed by SA accumulation, which in turn enhanced Hsfs binding to HSE, thereby activating non-systemic stimulation of basic and acidic PR gene expression. Disease severity in the first leaf was significantly reduced concomitantly with upregulation of PR gene expression when Pst was inoculated.

Supplementary Materials: The following are available online at http:/ /www.mdpi.com/2073-4395/9/1/2/s1, Figure S1: Changes in the relative expression level of (a) PR1b1, and (b) HsfA2.

Author Contributions: Conceptualization, N.A.A. and T.S.; Methodology, N.A.A., T.S., M.H.; Software, N.A.A. and M.H.; Validation, N.A.A., M.H. and T.S.; Formal Analysis, N.A.A. and T.S.; Investigation, N.A.A. and T.S.; Resources, N.A.A. and T.S.; Data Curation, N.A.A. and T.S.; Writing-Original Draft Preparation, N.A.A. and T.S.; Writing-Review and Editing, N.A.A. and T.S.; Visualization, N.A.A. and T.S.; Supervision, T.S., M.H., S.T. and I.O.; Project Administration, T.S.; Funding Acquisition, T.S.

Funding: This research was funded by JSPS KAKENHI grant number [17K07637].

Acknowledgments: The authors gratefully acknowledge the Ibaraki University Gene Research Center for providing technical assistance.

Conflicts of Interest: The authors declare no conflict of interest.

\section{References}

1. Widiastuti, A.; Yoshino, M.; Saito, H.; Maejima, K.; Zhou, S.; Odani, H.; Hasegawa, M.; Nitta, Y.; Sato, T. Induction of disease resistance against Botrytis cinerea by heat shock treatment in melon (Cucumis melo L.). Physiol. Mol. Plant Pathol. 2011, 75, 157-162. [CrossRef]

2. Widiastuti, A.; Yoshino, M.; Saito, H.; Maejima, K.; Zhou, S.; Odani, H.; Narisawa, K.; Hasegawa, M.; Nitta, Y.; Sato, T. Heat shock-induced resistance in strawberry against crown rot fungus Colletotrichum gloeosporioides. Physiol. Mol. Plant Pathol. 2013, 84, 86-91. [CrossRef]

3. Yoshino, M.; Widiastuti, A.; Hasegawa, M.; Sato, T. Induction of disease resistance against gray mold by heat shock using hot water dipping in cucumber and its underlying mechanism. Hortic. Res. 2011, 10, 429-433. [CrossRef]

4. Cronjé, M.J.; Bornman, L. Salicylic acid influences Hsp70/Hsc70 expression in Lycopersicon esculentum: Dose- and time-dependent induction or potentiation. Biochem. Biophys. Res. Commun. 2006, 427, 422-427. [CrossRef] [PubMed]

5. Cronjé, M.J.; Weir, I.E.; Bornman, L. Salicylic acid-mediated potentiation of Hsp70 induction correlates with reduced apoptosis in tobacco protoplasts. Cytometry Part A 2004, 61, 76-87. [CrossRef] [PubMed]

6. Liu, H.C.; Liaom, H.T.; Charng, Y.Y. The role of class A1 heat shock factors (HSFA1s) in response to heat and other stresses in Arabidopsis. Plant Cell Environ. 2011, 34, 738-751. [CrossRef] [PubMed] 
7. Liu, H.; Charng, Y. Acquired thermotolerance independent of heat shock factor A1 (HsfA1), the master regulator of the heat stress response. Plant Signal. Behav. 2012, 7, 547-550. [CrossRef]

8. Xue, G.P.; Sadat, S.; Drenth, J.; McIntyre, C.L. The heat shock factor family from Triticum aestivum in response to heat and other major abiotic stresses and their role in regulation of heat shock protein genes. J. Exp. Bot. 2014, 65, 539-557. [CrossRef]

9. Basra, A. Crop Responses and Adaptations to Temperature Stress: New Insights and Approaches; CRC Press/Taylor \& Francis: Baca Raton, FL, USA, 2000; Volume 223, ISBN 1-56022-890-3.

10. von Koskull-Döring, P.; Scharf, K.D.; Nover, L. The diversity of plant heat stress transcription factors. Trends Plant Sci. 2007, 12, 452-457. [CrossRef]

11. Nover, L.; Bharti, K.; Döring, P.; Mishra, S.K.; Ganguli, A.; Scharf, K.-D. Arabidopsis and the heat stress transcription factor world: How many heat stress transcription factors do we need? Cell Stress Chaperones 2001, 6, 177. [CrossRef] [PubMed]

12. Treuter, E.; Nover, L.; Ohme, K.; Scharf, K.D. Promoter specificity and deletion analysis of three heat stress transcription factors of tomato. Mol. Gen. Genet. 1993, 240, 113-125. [CrossRef] [PubMed]

13. Chan-Schaminet, K.Y.; Baniwal, S.K.; Bublak, D.; Nover, L.; Scharf, K.D. Specific interaction between tomato HsfA1 and HsfA2 creates hetero-oligomeric superactivator complexes for synergistic activation of heat stress gene expression. J. Biol. Chem. 2009, 284, 20848-20857. [CrossRef] [PubMed]

14. Hahn, A.; Bublak, D.; Schleiff, E.; Scharf, K.D. Crosstalk between Hsp90 and Hsp70 chaperones and heat stress transcription factors in tomato. Plant Cell 2011, 23, 741-755. [CrossRef] [PubMed]

15. Storozhenko, S.; De Pauw, P.; Van Montagu, M.; Inzé, D.; Kushnir, S. The heat-shock element is a functional component of the Arabidopsis APX1 gene promoter. Plant Physiol. 1998, 118, 1005-1014. [CrossRef] [PubMed]

16. Sato, Y.; Murakami, T.; Funatsuki, H.; Matsuba, S.; Saruyama, H.; Tanida, M. Heat shock-mediated APX gene expression and protection against chilling injury in rice seedlings. J. Exp. Bot. 2001, 52, 145-151. [CrossRef] [PubMed]

17. Kumar, M.; Busch, W.; Birke, H.; Kemmerling, B.; Nürnberger, T.; Schöffl, F. Heat shock factors HsfB1 and HsfB2b are involved in the regulation of Pdf1.2 expression and pathogen resistance in Arabidopsis. Mol. Plant 2009, 2, 152-165. [CrossRef]

18. Prodromou, C.; Roe, S.M.; O’Brien, R.; Ladbury, J.E.; Piper, P.W.; Pearl, L.H. Identification and structural characterization of the ATP/ADP-binding site in the Hsp90 molecular chaperone. Cell 1997, 90, 65-75. [CrossRef]

19. Moshe, A.; Gorovits, R.; Liu, Y.; Czosnek, H. Tomato plant cell death induced by inhibition of HSP90 is alleviated by Tomato yellow leaf curl virus infection. Mol. Plant Pathol. 2016, 17, 247-260. [CrossRef]

20. McConnell, J.R.; Buckton, L.K.; McAlpine, S.R. Regulating the master regulator: Controlling heat shock factor 1 as a chemotherapy approach. Bioorg. Med. Chem. Lett. 2015, 25, 3409-3414. [CrossRef]

21. Yoon, Y.J.; Kim, J.A.; Shin, K.D.; Shin, D.S.; Han, Y.M.; Lee, Y.J.; Lee, J.S.; Kwon, B.M.; Han, D.C. KB inhibits HSP70 synthesis through inhibition of heat shock factor 1 function by impairing the recruitment of positive transcription elongation factor $b$ to the hsp70 promoter. J. Biol. Chem. 2011, 286, 1737-1747. [CrossRef]

22. Tornero, P.; Gadea, J.; Conejero, V.; Vera, P. Two PR-1 genes from tomato are differentially regulated and reveal a novel mode of expression for a pathogenesis-related gene during the hypersensitive response and development. Mol. Plant Microbe Interact. 1997, 10, 624-634. [CrossRef] [PubMed]

23. Francia, D.; Demaria, D.; Calderini, O.; Ferraris, L.; Valentino, D.; Arcioni, S.; Tamietti, G.; Cardinale, F. Wounding induces resistance to pathogens with different lifestyles in tomato: Role of ethylene in cross-protection. Plant Cell Environ. 2007, 30, 1357-1365. [CrossRef] [PubMed]

24. Di Baccio, D.; Ederli, L.; Marabottini, R.; Badiani, M.; Francini, A.; Nali, C.; Antonelli, M.; Santangelo, E.; Sebastiani, L.; Pasqualini, S. Similar foliar lesions but opposite hormonal patterns in a tomato mutant impaired in ethylene perception and its near isogenic wild type challenged with ozone. Environ. Exp. Bot. 2012, 75, 286-297. [CrossRef]

25. Sato, T.; Yasuda, M.; Kubo, M.; Nakashita, H.; Arie, T.; Teraoka, T.; Takayanagi, R.; Yoneyama, Y.; Yoshida, S. Analysis of gray mold resistance of tomato induced by heat shock treatment. In Proceedings of the Abstracts of the 46th Annual Meeting of the Japanese Society of Plant Physiologists, Niigata, Japan, 24-26 March 2005. [CrossRef] 
26. Widiastuti, A.; Yoshino, M.; Hasegawa, M.; Nitta, Y.; Sato, T. Heat shock-induced resistance increases chitinase-1 gene expression and stimulates salicylic acid production in melon (Cucumis melo L.). Physiol. Mol. Plant Pathol. 2013, 82, 51-55. [CrossRef]

27. Stout, M.J.; Fidantsef, A.L.; Duffey, S.S.; Bostock, R.M. Signal interactions in pathogen and insect attack: Systemic plant-mediated interactions between pathogens and herbivores of the tomato, Lycopersicon esculentum. Physiol. Mol. Plant Pathol. 1999, 54, 115-130. [CrossRef]

28. Kumar, D. Salicylic acid signaling in disease resistance. Plant Sci. 2014, 228, 127-134. [CrossRef] [PubMed]

29. Derksen, H.; Rampitsch, C.; Daayf, F. Signaling cross-talk in plant disease resistance. Plant Sci. 2013, 207, 79-87. [CrossRef]

30. Park, S.W.; Kaimoyo, E.; Kumar, D.; Mosher, S.; Klessig, D.F. Methyl salicylate is a critical mobile signal for plant systemic acquired resistance. Science 2007, 318, 113-116. [CrossRef]

31. Larkindale, J. Protection against heat stress-induced oxidative damage in Arabidopsis involves calcium, abscisic acid, ethylene, and salicylic acid. Plant Physiol. 2002, 128, 682-695. [CrossRef]

32. Khan, M.I.R.; Iqbal, N.; Masood, A.; Per, T.S.; Khan, N.A. Salicylic acid alleviates adverse effects of heat stress on photosynthesis through changes in proline production and ethylene formation. Plant Signal. Behav. 2013, 8, e26374. [CrossRef]

33. Wang, L.J.; Fan, L.; Loescher, W.; Duan, W.; Liu, G.J.; Cheng, J.S.; Luo, H.B.; Li, S.H. Salicylic acid alleviates decreases in photosynthesis under heat stress and accelerates recovery in grapevine leaves. BMC Plant Biol. 2010, 10, 34. [CrossRef] [PubMed]

34. Snyman, M.; Cronjém, M.J. Modulation of heat shock factors accompanies salicylic acid-mediated potentiation of Hsp70 in tomato seedlings. J. Exp. Bot. 2008, 59, 2125-2132. [CrossRef] [PubMed]

35. Nover, L. Expression of heat shock genes in homologous and heterologous systems. Enzym. Microb. Technol. 1987, 9, 130-144. [CrossRef]

36. Hoffman, E.; Corces, V. Sequences involved in temperature and ecdysterone-induced transcription are located in separate regions of a Drosophila melanogaster heat shock gene. Mol. Cell. Biol. 1986, 6, 663-673. [CrossRef] [PubMed]

37. Goyal, R.K.; Fatima, T.; Topuz, M.; Bernadec, A.; Sicher, R.; Handa, A.K.; Mattoo, A.K. Pathogenesis-related protein $1 \mathrm{~b} 1$ (PR1b1) is a major tomato fruit protein responsive to chilling temperature and upregulated in high polyamine transgenic genotypes. Front. Plant Sci. 2016, 7, 901. [CrossRef] [PubMed] 